\title{
Luminescence spectroscopy of matrix-isolated atomic manganese: Site size and orbital occupancy dependence of crystal field splitting
}

\author{
Martin A. Collier, Owen Byrne, Ciaran Murray, and John G. McCaffrey ${ }^{\text {a) }}$ \\ Department of Chemistry, National University of Ireland-Maynooth, Maynooth, County Kildare, Ireland
}

(Received 17 December 2009; accepted 4 March 2010; published online 27 April 2010)

\begin{abstract}
Narrow linewidth emission features observed in the near-UV following $y^{6} \mathrm{P}$ state excitation of atomic manganese isolated in the solid rare gases are assigned to $b^{4} \mathrm{D}$ and $a^{4} \mathrm{P}$ states. These states arise from the $3 d^{5} 4 s^{2}$ electronic configuration, identical to that of the ${ }^{6} \mathrm{~S}$ ground state, and the origin of the narrow linewidths. Two thermally stable sites, labeled blue and red on the basis of their position in absorption spectra, are occupied by atomic $\mathrm{Mn}$ in $\mathrm{Ar}$ and $\mathrm{Kr}$ while a single site is present in Xe. The red site produces a single, narrow line emission for the $b^{4} \mathrm{D}$ state at $329 \mathrm{~nm}$. In contrast, a lineshape analysis of the complex blue site $b^{4} \mathrm{D}$ state emission between 331 and $332 \mathrm{~nm}$ reveals the occurrence of three zero phonon lines (ZPLs). Millisecond emission decay curves recorded for these features are found to be complex, requiring double and triple exponential fit functions. The origins of the complex decays and multiple ZPLs are shown to arise from weak crystal field splitting (CFS) of the $\mathrm{J}=7 / 2$ spin-orbit level of the $b^{4} \mathrm{D}$ state of atomic $\mathrm{Mn}$ isolated in the blue site of the solid rare gases. Fields of cubic symmetry are capable of inducing splitting for $\mathbf{J}>3 / 2$ so atoms isolated in both single vacancy and tetravacancy sites in the fcc lattices of the solid rare gases are prone to this effect. $b{ }^{4} \mathrm{D}$ state emission is also produced following $y^{6} \mathrm{P}$ excitation for $\mathrm{Mn}$ atoms occupying the red sites in Ar and Kr. However, Mn atoms isolated in the larger tetravacancy sites have small matrix shifts and do not exhibit any CFS. The magnitudes of the weak CF splittings are shown to depend on both the excited state electronic configurations $3 d^{5} 4 s^{2} b^{4} \mathrm{D}$ and $3 d^{6} 4 s^{1} a^{4} \mathrm{D}$ states and the size of the matrix site occupied by atomic Mn. (C) 2010 American Institute of Physics. [doi:10.1063/1.3374030]
\end{abstract}

\section{INTRODUCTION}

Previous studies of the luminescence spectroscopy of metal atoms isolated in the solid rare gases have shown that emission linewidths depend very strongly on the electronic configurations involved in the transitions. Thus, $p \rightarrow s$ transitions are now well known ${ }^{1}$ to be broad, exhibiting large Stokes'-shifted emission while $d \rightarrow s$ transitions are narrow and unshifted from their gas phase positions. This behavior emerged from the studies presented by Bondybey ${ }^{2}$ on atomic $\mathrm{Ca}$, Pellin et $\mathrm{al}^{3}{ }^{3}$ on $\mathrm{Cr}$ and Mo, Nixon and co-workers ${ }^{4}$ on $\mathrm{Fe}, \mathrm{Co}$, and $\mathrm{Ni}$ atoms, the groups of $\mathrm{Kolb}^{5}$ and Ozin ${ }^{6}$ on $\mathrm{Cu}$, $\mathrm{Ag}$, and $\mathrm{Au}$, and by the Maynooth group on $\mathrm{Zn},{ }^{7} \mathrm{Cd},{ }^{8}$ and $\mathrm{Hg} .{ }^{9} \quad$ Recently, we reported the luminescence spectroscopy $^{10,11}$ of matrix-isolated atomic $\mathrm{Mn}$ and found that while these conclusions are generally correct, another factor playing a significant role in determining the emission linewidth is the site of isolation. Contrary to expectation, it was established that certain sites are capable of considerable broadening on $d \rightarrow s$ transitions while others exhibit the normal characteristics of narrow and unshifted emission from the gas phase position. In a recent molecular dynamics study of matrix-isolated atomic sodium ${ }^{12}$ the nature of the sites occupied by this large atom was examined. As anticipated, large tetravacancy (TV) and hexavacancy sites were found in simulated depositions for $\mathrm{Na}$ in $\mathrm{Ar}$ and $\mathrm{Kr}$. However, upon

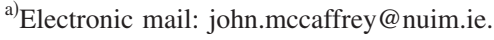

prolonged laser excitation novel "violet" sites were generated in these solids which were attributed to the "cramped" occupancy of sodium atoms in single vacancy (SV) sites.

We now extend a study of the effects of the trapping site on matrix-isolated metal atoms, by analyzing the splitting observed on the narrow emissions of distinct spin-orbit levels in certain sites and the complete absence of splitting in other sites. This study, conducted on the near-UV emission spectroscopy of atomic Mn, reveals the existence of weak crystal field splitting in the smaller sites of the solid rare gases. The near-UV emission bands studied result from photoexcitation of the strongest resonance, viz., the $[\mathrm{Ar}] 3 d^{5} 4 s 4 p \quad y{ }^{6} \mathrm{P} \leftarrow[\mathrm{Ar}] 3 d^{5} 4 s^{2} \quad a^{6} \mathrm{~S}$ transition $^{13}$ at 279.827 $\mathrm{nm}$ in the gas phase. ${ }^{13}$ The $3 d^{5} 4 s 4 p$ configuration gives rise to the $y^{6} \mathrm{P}$ and the $z{ }^{6} \mathrm{P}$ states, both of which are accessible in fully allowed electric-dipole transitions from the ${ }^{6} \mathrm{~S}$ ground state. In previous matrix absorption ${ }^{14}$ and magnetic circular dichroism (MCD) (Ref. 15) studies by Vala and coworkers, strong atomic Mn absorption bands were observed close to the position of these two gas phase transitions. However, the spectra were complex indicating occupancy of Mn atoms in multiple sites. More recently, excitation spectra ${ }^{16}$ recorded by our group indicated that atomic Mn isolated in solid $\mathrm{Kr}$ occupies only two distinct thermally stable sites. The blue site, tentatively attributed to SV occupancy, produces $y{ }^{6} \mathrm{P}$ state absorption at $279.2 \mathrm{~nm}$ and the red, TV site absorbs at $284 \mathrm{~nm}$. The corresponding bands are centered at 273 and $278 \mathrm{~nm}$ in the Mn/Ar system. Atomic Mn exists in a 


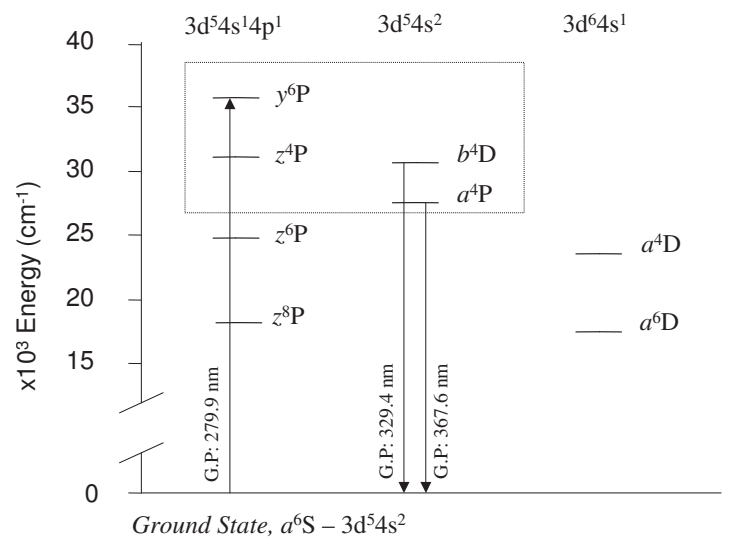

FIG. 1. A schematic of the energy levels of gas phase atomic manganese (Ref. 13). Luminescence in the present study is produced with photoexcitation of the fully allowed $y{ }^{6} \mathrm{P}_{5 / 2} \leftarrow a{ }^{6} \mathrm{~S}_{5 / 2}$ transition, occurring at $35726 \mathrm{~cm}^{-1}(279.91 \mathrm{~nm})$ in the gas phase, is indicated by the upward arrow. The area of the diagram shown in the dotted box highlights the excited states that exist immediately below the $y{ }^{6} \mathrm{P}$ state and which are accessible in relaxation occurring after $y{ }^{6} \mathrm{P} \leftarrow a^{6} \mathrm{~S}$ excitation. The gas phase transitions from the $a^{4} \mathrm{P}$ and $b{ }^{4} \mathrm{D}$ levels, which have the same $3 d^{5} 4 s^{2}$ configuration as the ground $a^{6} \mathrm{~S}_{5 / 2}$ state, are of particular importance to the present study. The wavelengths of these transitions are shown by the downward arrows.

single thermally stable site in xenon matrices, producing absorption at $288.2 \mathrm{~nm}$. The red site greatly dominates in Ar, while the blue site only slightly dominates in $\mathrm{Kr}$.

The excited states of atomic manganese energetically accessible with $y^{6} \mathrm{P}$ state excitation are shown in Fig. 1. Eleven excited states occur to lower energy than the $y{ }^{6} \mathrm{P}$ of which the $z^{4} \mathrm{P}, b^{4} \mathrm{D}, a^{4} \mathrm{P}, z^{6} \mathrm{P}, a^{4} \mathrm{D}, z^{8} \mathrm{P}$, and $a^{6} \mathrm{D}$ are shown. The luminescence produced with excitation of the lower energy $z{ }^{6} \mathrm{P} \leftarrow a{ }^{6} \mathrm{~S}$ resonance transition involves only the last four states. Since this work has been presented in an earlier paper, ${ }^{10}$ analysis of the emission from these lower energy states will not be repeated in this presentation, even though these bands are also produced with $y^{6} \mathrm{P} \leftarrow a^{6} \mathrm{~S}$ excitation. Interested readers are referred to Ref. 10 for details of the low energy emission bands. As indicated in Fig. 1, excitation of the $y^{6} \mathrm{P}$ state gives access to the $b^{4} \mathrm{D}$ and $a{ }^{4} \mathrm{P}$ states which have the same $3 d^{5} 4 s^{2}$ electronic configuration as the ground $a{ }^{6} \mathrm{~S}$ state. These states would be expected to produce narrower lines than the lower energy $3 d^{6} 4 s^{1} a^{4} \mathrm{D}$ and $a^{6} \mathrm{D}$ states, both of which involve $d \rightarrow s$ orbital transitions. In the present contribution, the site dependence of the emission from the $b^{4} \mathrm{D}$ and $a^{4} \mathrm{P}$ states is analyzed in detail.

This paper is structured as follows. Firstly, steady-state emission spectra recorded with continuous lamp excitation of the absorption features assigned to the $y^{6} \mathrm{P} \leftarrow a{ }^{6} \mathrm{~S}$ transition of atomic $\mathrm{Mn}$ isolated in the rare gases $\mathrm{Ar}, \mathrm{Kr}$, and $\mathrm{Xe}$ are presented. Excitation spectra recorded monitoring the resulting emission features are then presented which allow site identification. With this information, high-resolution emission spectra allow characterization of the observed emission lineshapes for Mn atoms isolated in specific sites. Excited state lifetime measurements, made with pulsed laser excitation, are used to assign the recorded emission bands to transitions of atomic manganese. Lineshape analyses conducted with the optical $W_{p}$ function $^{17}$ are used to locate the zero phonon lines (ZPLs) in complex emission bands. A crystal field analysis of the emission bands is conducted for $\mathrm{Mn}$ atoms isolated in sites of cubic symmetry. A general analysis of the presence of CFS on the lower energy $a^{4} \mathrm{D}$ and $a^{6} \mathrm{D}$ states is presented for the Mn atom occupying both small and large matrix sites.

\section{EXPERIMENTAL}

The experimental setup used for recording excitation and emission spectra has been described elsewhere. ${ }^{9,10,16}$ Briefly, a $0.5 \mathrm{~m}$ (Acton Research Corporation, model ARC SP500i) monochromator fitted with three gratings ${ }^{10}$ and a photon counting (Hamamatsu R928-P) photomultiplier tube cooled to $-20{ }^{\circ} \mathrm{C}$ were employed to record emission from $\mathrm{Mn} / \mathrm{RG}$ samples. Steady-state excitation was from a deuterium lamp (Hamamatsu L6310 and a Cathodeon C713 power supply) ${ }^{9}$ dispersed by a $0.3 \mathrm{~m}$ (ARC SP300i) monochromator. ${ }^{9}$ Pulsed excitation was achieved by doubling the output of a (Quantel, model TDL-90) dye laser, pumped by the second harmonic of a $10 \mathrm{~Hz}$ (Quantel, model YG-980E) Nd:YAG (yttrium aluminum garnate) laser. ${ }^{9}$ The wavelengths required for site-specific laser excitation of atomic manganese in the 273-288 nm spectral region were produced by doubling the output of the rhodamine 590 dye. A potassium dihydrogen phosphate crystal (Quantel, DCC3) was used for frequency doubling while a quartz crystal (Quantel, QCC1) was used to compensate for the walk of the resultant beams. ${ }^{10}$ Wavelength separation of the UV beam from the dye laser beam was achieved with a Pellin-Broca prism. Time resolved emission spectra (TRES) were recorded using an intensified gated iCCD (intensified charged coupled device) detector (Andor Technologies, model iStar DH720) mounted on the SP500i imaging spectrograph. ${ }^{10}$ Nanosecond decay curves were obtained by taking slices of the TRES at specific emission wavelengths. Emission decays on microsecond and longer timescales were recorded, as described elsewhere, ${ }^{9}$ with photon counting using a $2 \mathrm{GHz}$ (FastComTec, model 7886) multichannel scaler.

The gas handling system and vacuum apparatus used in the preparation of $\mathrm{Mn} / \mathrm{RG}$ matrix samples has been described in previous publications from our group. ${ }^{10,16}$ Manganese vapor was generated by electron bombardment of Mn metal contained in a Mo crucible. The emission spectra reported in this study were recorded in the most dilute $\mathrm{Mn} / \mathrm{RG}$ samples formed. As shown in our previous absorption work, ${ }^{16}$ these samples contain predominately isolated atomic manganese. Because of the extent of the site and state-specific emissions observed in the $\mathrm{Mn} / \mathrm{RG}$ matrix systems, only spectra recorded in annealed samples are presented in this contribution.

\section{RESULTS AND ANALYSIS}

\section{A. Emission}

A summary of the near-UV emission features produced ${ }^{18}$ with excitation of the $y^{6} \mathrm{P} \leftarrow a{ }^{6} \mathrm{~S}$ transition is presented in Fig. 2 for the $\mathrm{Mn} / \mathrm{Ar}, \mathrm{Mn} / \mathrm{Kr}$, and $\mathrm{Mn} / \mathrm{Xe}$ systems. The recorded emission bands fall into two main categories; those around $330 \mathrm{~nm}$ and those near $370 \mathrm{~nm}$. In Xe an additional 


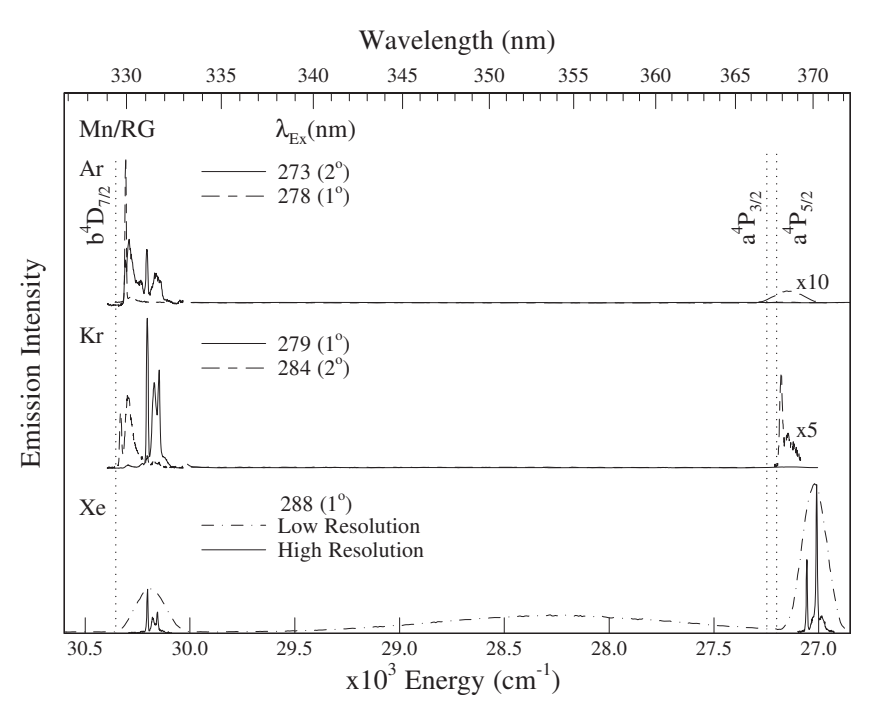

FIG. 2. Emission spectra recorded at $12 \mathrm{~K}$ for the $\mathrm{Mn} / \mathrm{Ar}, \mathrm{Mn} / \mathrm{Kr}$, and $\mathrm{Mn} / \mathrm{Xe}$ systems with site-selective lamp excitation of the Mn $y{ }^{6} \mathrm{P} \leftarrow a{ }^{6} \mathrm{~S}$ transition. The excitation wavelengths used are indicated on the left by $\lambda_{\mathrm{Ex}}$ in wavelength units. The relative amounts of the red and blue sites occupied in solid $\mathrm{Ar}$ and $\mathrm{Kr}$ are presented in brackets as either primary (1) or secondary (2). The effect of resolution is shown for the $\mathrm{Mn} / \mathrm{Xe}$ data in lowest trace. All spectra were recorded following Mn/RG sample annealing. The spectral positions of the gas phase transitions of atomic Mn are shown by the dashed vertical lines.

broad band, evident in the low resolution scan on the bottom of Fig. 2, is centered at $354 \mathrm{~nm}$. It is obvious in Fig. 2, that the $330 \mathrm{~nm}$ bands are only slightly redshifted from the $b{ }^{4} \mathrm{D}_{(\mathrm{J}=7 / 2)} \rightarrow a^{6} \mathrm{~S}_{5 / 2}$ transition occurring at $329.44 \mathrm{~nm}$ in the gas phase. The $370 \mathrm{~nm}$ bands are similarly redshifted from the $a{ }^{4} \mathrm{P}_{(\mathrm{J}=5 / 2)} \rightarrow a^{6} \mathrm{~S}_{5 / 2}$ transition at $367.63 \mathrm{~nm}$. Both sets of bands at 330 and $370 \mathrm{~nm}$ are spectrally narrow $\left(<10 \mathrm{~cm}^{-1}\right)$ and, due to the small matrix shifts, can be assigned with confidence to the $b^{4} \mathrm{D}$ and $a^{4} \mathrm{P}$ states, respectively. The width of the Mn/Ar band centered at $368.5 \mathrm{~nm}$ arises because of the low resolution used to record this weak feature-its true lineshape has not been determined in this study. The effect of the resolution used is illustrated by the $\mathrm{Mn} / \mathrm{Xe}$ spectra shown on the bottom of Fig. 2. In the following sections, luminescence of the $3 d^{5} 4 s 4 p$ y ${ }^{6} \mathrm{P}$ state and details of the emission features resulting from the $3 d^{5} 4 s^{2} \quad b^{4} \mathrm{D}$ and $3 d^{5} 4 s^{2} a{ }^{4} \mathrm{P}$ states are presented. Because the emission features in the three rare gases are observed to be site-specific, the results will be reported separately for the thermally stable red and blue sites.

\section{B. $\operatorname{Mn}\left(y^{6} \mathrm{P}\right) / \mathrm{RG}$ fluorescence}

The most pronounced difference, evident in Fig. 2, between $\mathrm{Mn} / \mathrm{Xe}$ and the other $\mathrm{Mn} / \mathrm{RG}$ systems is the existence of the broad, featureless band centered at $354 \mathrm{~nm}$. The state assignment of this band is not as straightforward as the narrow bands at 330 and $370 \mathrm{~nm}$. To obtain an assignment for the $354 \mathrm{~nm}$ band, its excitation spectrum and emission decay were recorded, the results of which are shown in Fig. 3. The fully allowed $y^{6} \mathrm{P} \leftrightarrow{ }^{6} \mathrm{~S}$ resonance transition occurs at $279.9 \mathrm{~nm}$ in the gas phase and the $\mathrm{Mn} / \mathrm{Xe}$ excitation band at $288.2 \mathrm{~nm}$, shown on the bottom left in Fig. 3, corresponds to the previously recorded atomic absorption. An emission de-

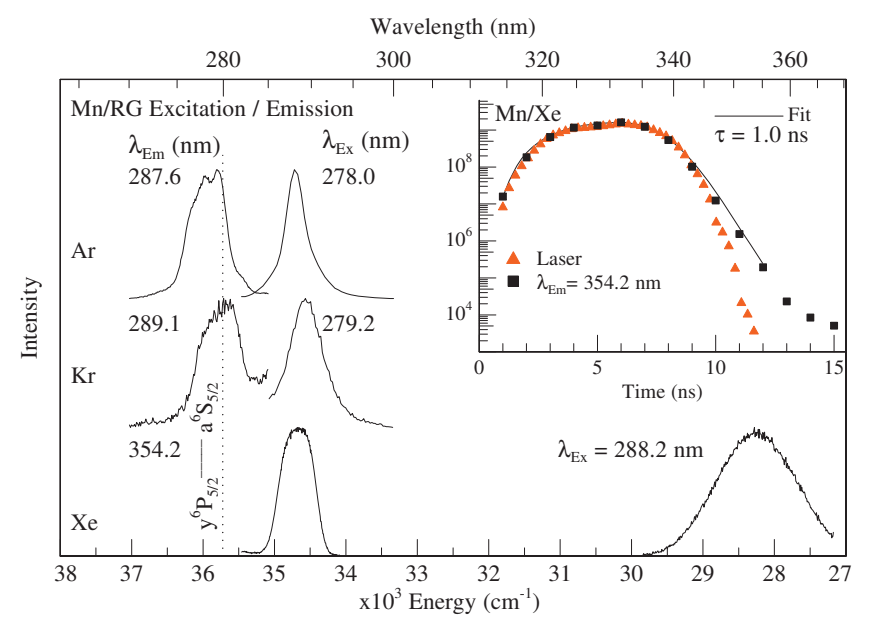

FIG. 3. Luminescence spectra recorded at $12 \mathrm{~K}$ for the $\mathrm{Mn} / \mathrm{RG}$ systems in the region of the gas phase $y^{6} \mathrm{P} \leftrightarrow a^{6} \mathrm{~S}$ transition of atomic manganese at $279.9 \mathrm{~nm}\left(35725.85 \mathrm{~cm}^{-1}\right)$, indicated by the dotted vertical line. The excitation wavelengths used to record the emission spectra are indicated in the middle by $\lambda_{E x}$ in nanometer units. Excitation spectra are presented for each system monitoring the emission bands at wavelengths indicated as $\lambda_{\mathrm{Em}}$ (nm). The $\mathrm{Mn} / \mathrm{Ar}, \mathrm{Mn} / \mathrm{Kr}$, and $\mathrm{Mn} / \mathrm{Xe}$ samples were deposited at $12 \mathrm{~K}$ and annealed to 30,37 , and $62 \mathrm{~K}$, respectively. The inset shows the decay profile recorded with iCCD detection of the broad $\mathrm{Mn} / \mathrm{Xe}$ emission centered at $356 \mathrm{~nm}$. The temporal profile of the pulsed dye laser is indicated by the triangles. The result of fitting the decay profile with a trial single exponential function convoluted with the laser temporal profile is also presented.

cay profile extracted at $356 \mathrm{~nm}$ from the TRES indicates a lifetime of $1.0 \mathrm{~ns}$ for this band as shown in the inset of Fig. 3. The gas phase lifetime ${ }^{19}$ of the $y{ }^{6} \mathrm{P}$ state of atomic manganese is $2.6 \mathrm{~ns}$, and the recorded matrix value closely matches this value when it is corrected for the effective field of the solid. Accordingly, we assign the broad $354 \mathrm{~nm}$ emission band in $\mathrm{Mn} / \mathrm{Xe}$ to $y^{6} \mathrm{P} \rightarrow a{ }^{6} \mathrm{~S}$ fluorescence.

The corresponding $y^{6} \mathrm{P}$ state emission bands of $\mathrm{Mn} / \mathrm{Ar}$ and $\mathrm{Mn} / \mathrm{Kr}$ are at 287.6 and $289.1 \mathrm{~nm}$, respectively, as shown in Fig. 3. The emission bands in these two systems are very weak relative to the narrow bands presented in Fig. 2. A comparison of the $\mathrm{Mn} / \mathrm{Ar}$ and $\mathrm{Mn} / \mathrm{Kr}$ fluorescence excitation spectra with the absorption spectra shown in Fig. 5 of Ref. 16 reveals that only the dominant absorption sites have been picked up in the ${ }^{6} \mathrm{P}$ state excitation scans. It is also evident in Fig. 3 that the emissions in $\mathrm{Mn} / \mathrm{Ar}$ and $\mathrm{Mn} / \mathrm{Kr}$ exhibit much smaller Stokes shifts than the Mn/Xe system. Values of approximately $1250 \mathrm{~cm}^{-1}$ have been determined in $\mathrm{Ar}$ and $\mathrm{Kr}$ while it is $6450 \mathrm{~cm}^{-1}$ in Xe. However, the nanosecond decay times extracted for the bands in the $\mathrm{Ar}$ and $\mathrm{Kr}$ systems indicate they also arise from the $y^{6} \mathrm{P} \rightarrow a{ }^{6} \mathrm{~S}$ transition.

\section{C. $330 \mathrm{~nm}$ luminescence}

\section{State assignments}

The intense, structured emission bands in the $330 \mathrm{~nm}$ spectral region are shown in Fig. 4 on an expanded scale revealing striking resemblances in the three hosts studied. The labels "blue site" and "red site" used for the emission in this figure pertain to relative spectral positions of their excitation/absorption bands (reported previously) ${ }^{10}$ and not their emission locations. Assignment of the sharp, red site bands at 329.96 and $329.70 \mathrm{~nm}$ in $\mathrm{Ar}$ and $\mathrm{Kr}$, respectively, to 


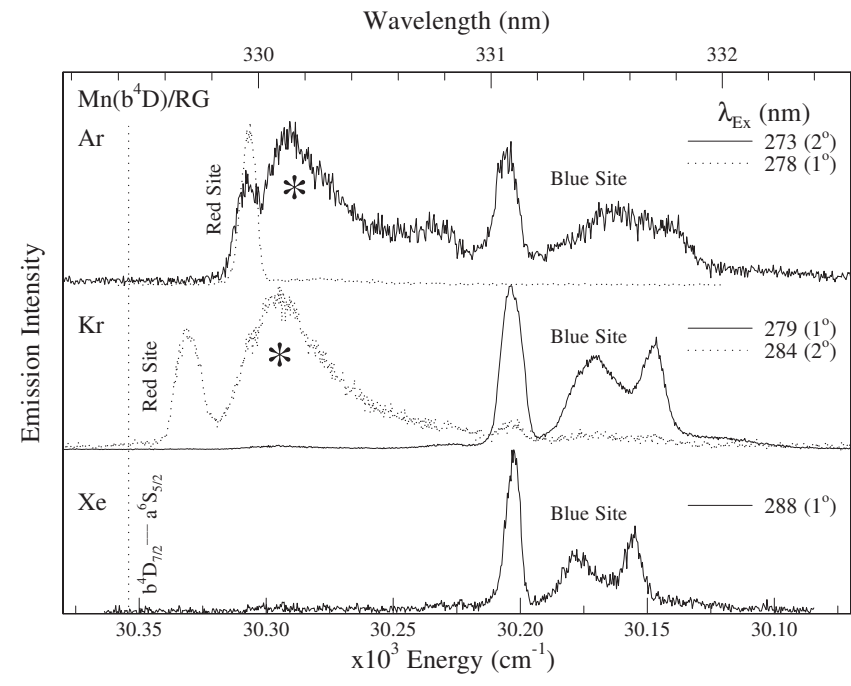

FIG. 4. Site dependence of the high-resolution emission spectra recorded at $12 \mathrm{~K}$ in the vicinity of the gas phase $b^{4} \mathrm{D} \leftrightarrow a^{6} \mathrm{~S}$ transition following sitespecific (red/blue) $y{ }^{6} \mathrm{P} \leftarrow a{ }^{6} \mathrm{~S}$ excitation of atomic Mn isolated in $\mathrm{Ar}, \mathrm{Kr}$, and Xe. The spectral position of the lowest energy $\mathrm{J}=7 / 2$ spin-orbit level of the $b^{4} \mathrm{D}$ state is indicated by the dotted vertical line at $329.44 \mathrm{~nm}$ (30 $354.21 \mathrm{~cm}^{-1}$ ). Emission produced with blue [single substitutional (SV)] site and red (TV) site excitation in $\mathrm{Ar}, \mathrm{Kr}$, and $\mathrm{Xe}$ are presented as solid and dotted lines, respectively. The excitation wavelengths used are indicated by $\lambda_{\mathrm{Ex}}$ in wavelength units. The asterisks identify emission bands produced with excitation of a thermally unstable matrix site.

$b^{4} \mathrm{D}_{(\mathrm{J}=7 / 2)} \rightarrow a^{6} \mathrm{~S}_{5 / 2}$ emission of atomic manganese is direct as this transition, shown by the dotted vertical line, occurs at $329.44 \mathrm{~nm}$ in the gas phase. The origin of the three resolved features present between 331 and $332 \mathrm{~nm}$ cannot, however, be immediately established. For instance, other spin-orbit $(\mathrm{J}=1 / 2,5 / 2$, and $3 / 2)$ levels of the $b^{4} \mathrm{D}$ state exist but they are at higher energy and with intervals in the gas phase ( 8 and $6 \mathrm{~cm}^{-1}$ ) quite different to the observed matrix splittings of 26 and $21 \mathrm{~cm}^{-1}$. Previous data obtained by our Group $^{20}$ with direct excitation of the forbidden $a^{6} \mathrm{D}_{\mathrm{J}}$ $\leftarrow a^{6} \mathrm{~S}$ transition demonstrate that the gas phase splitting between spin-orbit levels is maintained in the matrix environment. Inspection of Fig. 1 reveals that no other D states of atomic $\mathrm{Mn}$ occur in the near-UV region. The $z{ }^{4} \mathrm{P}_{(5 / 2)} \leftrightarrow a{ }^{6} \mathrm{~S}_{5 / 2}$ transition occurs at $322.57 \mathrm{~nm}$ (31 $001 \mathrm{~cm}^{-1}$ ) in the gas phase ${ }^{13}$ but since this excited state arises from the "triplet-like" $3 d^{5} 4 s 4 p$ electronic configuration, this open $\mathrm{p}$-shell configuration should produce a broad, strongly Stokes-shifted emission in solid Xe, not the narrow lines observed. The corresponding low energy "tripletlike" $3 d^{5} 4 s 4 p \quad z{ }^{8} \mathrm{P}$ state was not observed in solid Xe following direct laser excitation. ${ }^{16}$ By a process of elimination the 331$332 \mathrm{~nm}$ matrix emission features observed in all three solid hosts must arise from the $\mathrm{J}=7 / 2$ level of the excited $b^{4} \mathrm{D}$ state of atomic Mn but the origin of the complex structure on the blue site emission requires analysis which will be presented next.

\section{Blue site emission}

$\mathrm{Mn} / \mathrm{Xe}$ offers the ideal starting point to analyze the bands in the 331-332 $\mathrm{nm}$ range since all the emission features in this system arise from a single site. The blue site emission in $\mathrm{Mn} / \mathrm{Xe}$, shown by the solid-trace on the bottom of Fig. 4, exhibits three narrow features at 331.09, 331.38, and $331.6 \mathrm{~nm}$. The most intense feature at $331.09 \mathrm{~nm}$ (30 $203 \mathrm{~cm}^{-1}$ ) exhibits a full width at half maximum (FWHM) of $6.4 \mathrm{~cm}^{-1}$ and a red matrix shift of $151 \mathrm{~cm}^{-1}$ from the $b^{4} \mathrm{D}_{(\mathrm{J}=7 / 2)} \rightarrow a^{6} \mathrm{~S}_{5 / 2}$ gas phase position. The emission decay curves recorded for the structured features were all in the $1 \mathrm{~ms}$ region. Adequate fitting required double exponential functions, the details of which are given in Table I and shown in the bottom panel of Fig. 5. Temperature dependent emission spectra for these features are presented in Fig. 5. Inspection of the $\mathrm{Mn} / \mathrm{Xe}$ data presented in the lower panel reveals that at $24 \mathrm{~K}$, the highest and lowest energy features lose some intensity with respect to the central component. At the higher temperature, an additional narrow feature (FWHM $\left.10 \mathrm{~cm}^{-1}\right)$ is evident at $330.8 \mathrm{~nm}\left(30223 \mathrm{~cm}^{-1}\right)$, blueshifted by about $20 \mathrm{~cm}^{-1}$ from the most intense feature in the $12 \mathrm{~K}$ spectrum. On returning to $12 \mathrm{~K}$ the original spectrum was regained indicating the temperature dependence observed was completely reversible. This behavior is characteristic of resolved phonon structure.

The blue site $331 \mathrm{~nm}$ emission features in $\mathrm{Kr}$ and $\mathrm{Xe}$ matrices reveal very similar splitting patterns when recorded under high resolution. Thus, as shown in Fig. 4, both $\mathrm{Mn} / \mathrm{Xe}$ and $\mathrm{Mn} / \mathrm{Kr}$ exhibit a dominant sharp $\left(\mathrm{FWHM}=9.5 \mathrm{~cm}^{-1}\right)$ line at $331.087 \mathrm{~nm}\left(30203.5 \mathrm{~cm}^{-1}\right)$ and a pair of resolved lines at lower energy with approximately half the intensity of the blue feature. The two red bands are centered at 30173 and $30147 \mathrm{~cm}^{-1}$ in $\mathrm{Kr}$ and at 30179 and $30157 \mathrm{~cm}^{-1}$ in Xe. With the exception of the emergence of hot emission bands, doubling the temperature had no effect on the line positions and produced only a slight increase in the relative intensity of the central band. The narrow linewidths and the lack of pronounced temperature dependence of the three resolved bands indicate a system with very weak electronphonon coupling. Accordingly, the three bands of the blue site present in Fig. 5 are identified as three ZPLs, with weak phonon sidebands responsible for the unresolved background.

To determine the actual positions of the three ZPLs in the $\mathrm{Mn} / \mathrm{Kr}$ and $\mathrm{Mn} / \mathrm{Xe}$ systems, lineshape analyses were conducted on the recorded emission bands with the $W_{p}$ optical function. This function, described in detail by Struck and Fonger, ${ }^{17}$ provides an analytic expression for the FranckCondon intensity factors for displaced harmonic oscillators. It assumes the dominance of a single phonon mode with a frequency $\hbar \omega$, an average value for the ground and excited electronic states coupled in the transition. The $W_{p}$ lineshape analysis allows, as shown in our earlier work, ${ }^{9}$ identification of the band origin, $\nu_{0,0}$, i.e., the ZPL and an assessment of the electron-phonon coupling strength $S$, for the electronic transition involved. The starting point for the $W_{p}$ lineshape fit is the selection of a value for the phonon frequency $(\hbar \omega)$ required to transform the recorded spectrum into phonon units, $p$.

The presence of resolved hot emission bands in the high temperature spectra allows direct measurement of the magnitude of the phonon frequency $\hbar \omega$. Values of 25 and $19 \mathrm{~cm}^{-1}$ were identified in this manner for $\mathrm{Mn} / \mathrm{Kr}$ and $\mathrm{Mn} /$ 
TABLE I. Photophysical characteristics and excited state assignments of the emission features produced with excitation of the $3 d^{5} 4 s 4 p \quad y{ }^{6} \mathrm{P}$ $\leftarrow 3 d^{5} 4 s^{2} a^{6} \mathrm{~S}$ transition of atomic manganese isolated in the two thermally stable sites in $\mathrm{Ar}$ and $\mathrm{Kr}$ and the single site in Xe. $\lambda$ indicates the emission band center in units of nanometers. The full width at half-maximum intensity of the emission features is denoted by $\Delta$ and the matrix shift by $\delta$. Both quantities are provided in wavenumber $\left(\mathrm{cm}^{-1}\right)$ units. The observed excited state radiative lifetimes are presented where $\tau_{\mathrm{obs}}$ indicates the lifetime of the dominant decay component at $12 \mathrm{~K}$. The question marks indicate state assignments that are only tentative.

\begin{tabular}{|c|c|c|c|c|c|}
\hline State & $\nu\left(\mathrm{cm}^{-1}\right)$ & Band $\lambda(\mathrm{nm})$ & $\Delta\left(\mathrm{cm}^{-1}\right)$ & $\delta\left(\mathrm{cm}^{-1}\right)$ & $\tau_{\text {obs }}$ \\
\hline \multicolumn{6}{|c|}{ Mn gas phase } \\
\hline$y{ }^{6} \mathrm{P}_{3 / 2}$ & 35690 & 280.19 & $\cdots$ & $\cdots$ & $2.6 \mathrm{~ns}$ \\
\hline$b^{4} \mathrm{P}_{5 / 2}$ & 33825 & 295.64 & $\cdots$ & $\cdots$ & \\
\hline$z^{4} \mathrm{P}_{5 / 2}$ & 31001 & 322.57 & $\ldots$ & $\ldots$ & \\
\hline$b^{4} \mathrm{D}_{7 / 2}$ & 30354 & 329.45 & $\ldots$ & $\ldots$ & \\
\hline$a{ }^{4} \mathrm{P}_{5 / 2}$ & 27202 & 367.62 & $\cdots$ & $\cdots$ & \\
\hline \multicolumn{6}{|c|}{$\mathrm{Mn} /$ Ar blue $\left(2^{\circ}\right)$ site } \\
\hline$b^{4} \mathrm{D}_{7 / 2}$ & 30206 & 331.06 & 10 & -148 & $\cdots$ \\
\hline$a^{4} \mathrm{P}(?)$ & 27137 & 368.5 & $\cdots$ & $-65(?)$ & $\cdots$ \\
\hline \multicolumn{6}{|c|}{$\mathrm{Mn} / \mathrm{Kr}$ blue $\left(1^{\circ}\right)$ site } \\
\hline$y^{6} \mathrm{P}$ & 34551 & 289.42 & 468 & -1139 & $<1 \mathrm{~ns}$ \\
\hline$b^{4} \mathrm{D}_{7 / 2}$ & 30204 & 331.08 & 9.4 & -150 & $2.78 \mathrm{~ms}$ \\
\hline \multicolumn{6}{|c|}{$\mathrm{Mn} / \mathrm{Xe}$} \\
\hline$y^{6} \mathrm{P}$ & 28234 & 354.2 & 1392 & -7456 & $1 \mathrm{~ns}$ \\
\hline$b^{4} \mathrm{D}_{7 / 2}$ & 30203 & 331.09 & 6.4 & -151 & $1.51 \mathrm{~ms}$ \\
\hline$a^{4} \mathrm{P}_{3 / 2}$ & 27057 & 369.59 & 6.4 & -191 & $12.6 \mathrm{~ms}$ \\
\hline$a{ }^{4} \mathrm{P}_{5 / 2}$ & 27010 & 370.23 & 6.7 & -192 & $15.4 \mathrm{~ms}$ \\
\hline \multicolumn{6}{|c|}{$\mathrm{Mn} / \mathrm{Ar}$ red $\left(1^{\circ}\right)$ site } \\
\hline$y^{6} \mathrm{P}$ & 34718 & 288.03 & 322 & -972 & $<1 \mathrm{~ns}$ \\
\hline$b^{4} \mathrm{D}_{7 / 2}$ & 30307 & 329.96 & 6.8 & -47 & $794 \mu \mathrm{s}$ \\
\hline \multicolumn{6}{|c|}{$\mathrm{Mn} / \mathrm{Kr}$ red $\left(2^{\circ}\right)$ site } \\
\hline$b^{4} \mathrm{D}_{7 / 2}$ & 30331 & 329.70 & 10 & -23 & $1.33 \mathrm{~ms}$ \\
\hline$a^{4} \mathrm{P}$ & 27181 & 367.9 & 10 & -21 & $1.36 \mathrm{~ms}$ \\
\hline
\end{tabular}

Xe, respectively. A satisfactory fit was obtained in the $\mathrm{Mn} / \mathrm{Kr}$ system with $\mathrm{S}=0.23$ and three ZPLs at 30204,30171 , and $30149 \mathrm{~cm}^{-1}$. The results of this fit are shown on the left in Fig. 6 at $12 \mathrm{~K}$ and on the right for $22 \mathrm{~K}$. The high temperature fit correctly describes the intensity increase of the "hot" emission at $30229 \mathrm{~cm}^{-1}$ to the blue of the ZPL and otherwise, little change in the emission profile. The lack of a strong temperature dependence is a direct result of the very small $\mathrm{S}$ value extracted in the fit. In $\mathrm{Mn} / \mathrm{Xe}$ a satisfactory fit was obtained with $\hbar \omega=19.0 \mathrm{~cm}^{-1}, \mathrm{~S}=0.26$, and three ZPLs at 30 204, 30177 , and $30157 \mathrm{~cm}^{-1}$. For $\mathrm{Mn} / \mathrm{Ar}$ the $W_{p}$ lineshape analysis was not as reliable due to the weakness of the blue site emission, however, an acceptable fit was obtained with $\hbar \omega=32 \mathrm{~cm}^{-1}, \mathrm{~S}=0.20$, and ZPLs at 30205,30165 , and $30144 \mathrm{~cm}^{-1}$. For a given matrix system all the fits were conducted with the same $S$ and $\hbar \omega$ values for the three ZPLs identified. The relative intensity of the ZPLs was an adjustable parameter but was found to be 2:1:1 for the 7/2 level of the excited $b^{4} \mathrm{D}$ state. The parameters extracted from the $W_{p}$ fits of the blue site emission in the three rare gases studied are collected in Table II.

\section{Red site emission}

With red (TV) site excitation in solid Ar and $\mathrm{Kr}$ single, intense peaks are observed at 329.96 and $329.7 \mathrm{~nm}$, respectively, as shown by the dotted traces in Fig. 4. Energetically

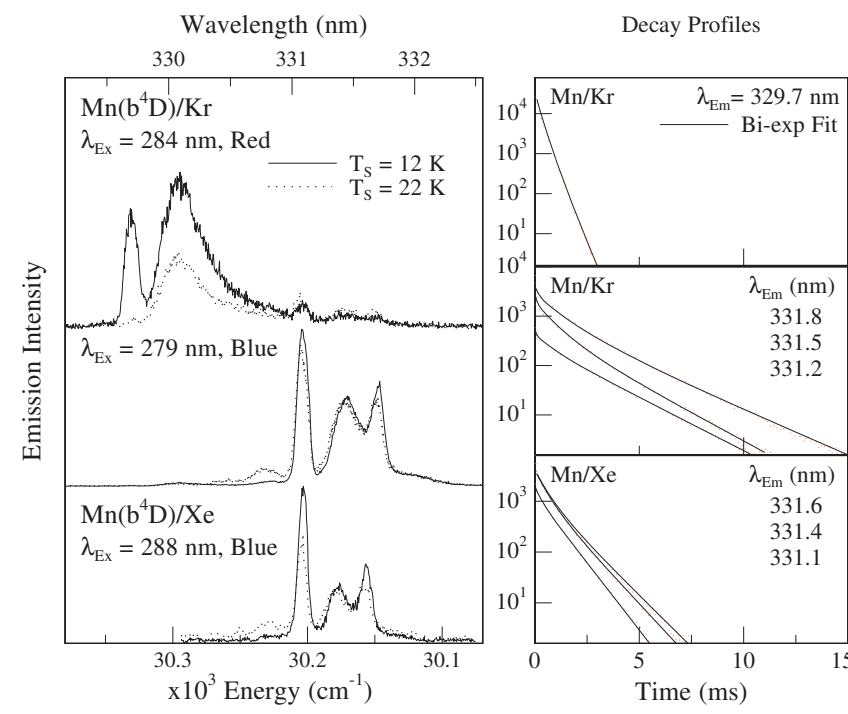

FIG. 5. The temperature dependence of high-resolution emission spectra recorded in the vicinity of the gas phase $b^{4} \mathrm{D}_{7 / 2} \leftrightarrow a{ }^{6} \mathrm{~S}$ transition of $\mathrm{Mn}$ isolated in solid $\mathrm{Kr}$ and $\mathrm{Xe}$ following site-specific (red/blue) $y{ }^{6} \mathrm{P} \leftarrow a{ }^{6} \mathrm{~S}$ pulsed laser excitation. The blue site emissions in $\mathrm{Kr}$ and $\mathrm{Xe}$ exhibit little temperature dependence while the narrow red site $329.7 \mathrm{~nm}$ emission in $\mathrm{Kr}$ is nearly completely removed at $22 \mathrm{~K}$. $\mathrm{T}_{\mathrm{s}}$ denotes the temperature at which the spectra were recorded and $\lambda_{\mathrm{Ex}}$ indicates the excitation wavelength. On the right emission decay profiles of the dominant thermally stable bands recorded at $12 \mathrm{~K}$ using photon counting and multichannel scaling are shown as dots. The results of trial biexponential fits of the decay profiles are presented as solid lines. 


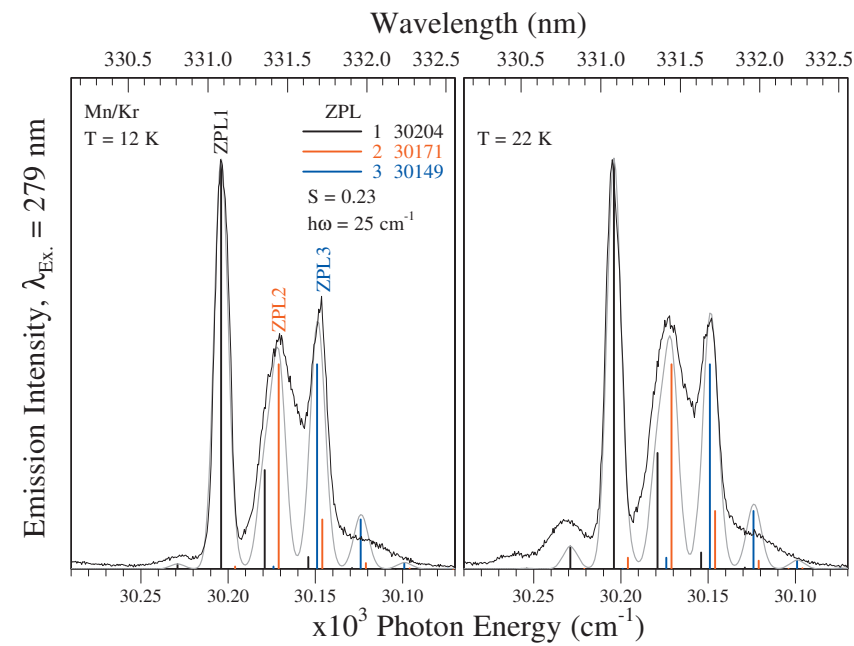

FIG. 6. Simulations of high-resolution $b^{4} \mathrm{D}_{7 / 2}$ state emission spectra recorded at 12 and $24 \mathrm{~K}$ with pulsed laser excitation at $279 \mathrm{~nm}$ of the thermally stable, blue site occupied by atomic Mn in solid krypton. Fits of the resolved phonon features were generated with the $W_{p}$ line shape functions using three ZPLs whose values are indicated in the plot as ZPL1, ZPL2, and ZPL3 in wavenumber units. The relative intensities of the three ZPLs were $2: 1: 1$, as indicted by the height of the three strongest vertical lines shown in black, red, and blue. Simulations of the emission band profiles were generated by convoluting the line distributions in each of the three $W_{p}$ fit functions, described in the text, with $6.6 \mathrm{~cm}^{-1}$ (FWHM) Gaussians. The presence of hot-phonon emission is most evident on the high energy side of ZPL1 in the $22 \mathrm{~K}$ scan shown on the right.

the closest transition of atomic manganese is the $b^{4} \mathrm{D}_{(\mathrm{J}=7 / 2)}$ $\rightarrow a{ }^{6} \mathrm{~S}_{5 / 2}$ transition, which occurs at $329.44 \mathrm{~nm}$ in the gas phase. Thus, the $329.96 \mathrm{~nm}$ emission in Ar clearly originates from the $\mathrm{J}=7 / 2$ level of the excited $b^{4} \mathrm{D}$ state of atomic $\mathrm{Mn}$. Decay profiles recorded monitoring the narrow emission in $\mathrm{Ar}$ and $\mathrm{Kr}$ were fit with double exponential functions. The dominant decay components extracted for $\mathrm{Ar}$ and $\mathrm{Kr}$ were of the order of $1 \mathrm{~ms}$ reinforcing the assignment to the spin and parity forbidden $b{ }^{4} \mathrm{D}_{(\mathrm{J}=7 / 2)} \rightarrow a{ }^{6} \mathrm{~S}_{5 / 2}$ transition of atomic Mn. Table I presents the photophysical properties of the $330 \mathrm{~nm}$ emission features following red site excitation in solid $\mathrm{Ar}$ and $\mathrm{Kr}$. Emission spectra recorded for $\mathrm{Mn} / \mathrm{Kr}$ at $22 \mathrm{~K}$, shown in the top left panel of Fig. 5, indicate that the narrow emission at $329.7 \mathrm{~nm}$ is completely removed at high temperature. It is noteworthy that the $b^{4} \mathrm{D}, \mathrm{J}=7 / 2$ state emission shows no discernable structure for $\mathrm{Mn}$ atoms in the larger red site present in $\mathrm{Ar}$ and $\mathrm{Kr}$. The linewidth of the bands present in the spectra is limited by the $5 \mathrm{~cm}^{-1}$ resolving power of the $0.5 \mathrm{~m}$ monochromator used to record emission.

\section{D. $370 \mathrm{~nm}$ luminescence \\ 1. Blue site emission}

Excitation of $y^{6} \mathrm{P}$ state $\mathrm{Mn}$ in solid Xe also produces the two narrow emission features at 369.59 and $370.23 \mathrm{~nm}$ shown in Fig. 7. The closest gas phase transitions to the pair of sharp emission features at $370 \mathrm{~nm}$ are the $a{ }^{4} \mathrm{P}_{3 / 2,5 / 2}$ $\rightarrow a{ }^{6} \mathrm{~S}$ transitions occurring at $367.00 \mathrm{~nm}\left(27248.00 \mathrm{~cm}^{-1}\right)$ and $367.62 \mathrm{~nm}\left(27201.54 \mathrm{~cm}^{-1}\right)$, respectively. The difference in energy between the two matrix peaks is $46 \mathrm{~cm}^{-1}$ identical, within the accuracy of our emission monochromator, to the gas phase splitting between the $a^{4} \mathrm{P}_{3 / 2}$ and $a^{4} \mathrm{P}_{5 / 2}$ atomic transitions $\left(46.46 \mathrm{~cm}^{-1}\right)$. Thus, these two intense peaks at 369.59 and $370.23 \mathrm{~nm}$ are assigned as emission from the $\mathrm{J}=3 / 2$ and $\mathrm{J}=5 / 2$ spin-orbit levels, respectively, of the $a^{4} \mathrm{P}$ state-both transitions in Xe exhibit a redshift of $191.5 \mathrm{~cm}^{-1}$ as illustrated in Fig. 7. The $a{ }^{4} \mathrm{P}$ state has the same $3 d^{5} 4 s^{2}$ electronic configuration as the ground state, this accounts for the narrow lineshapes observed. The emission decay curves of both features were satisfactorily

TABLE II. Spectral positions for the narrow-band emission features assigned to the $b{ }^{4} \mathrm{D}_{7 / 2} \rightarrow a{ }^{6} \mathrm{~S}$ and $a{ }^{4} \mathrm{D}_{7 / 2} \rightarrow a{ }^{6} \mathrm{~S}$ transitions of atomic manganese produced with excitation of the $y{ }^{6} \mathrm{P}$ and $z{ }^{6} \mathrm{P}$ transitions, respectively. The $b{ }^{4} \mathrm{D}_{7 / 2}$ emission is carried by Mn atoms isolated in substitutional (blue) sites in $\mathrm{Ar}, \mathrm{Kr}$, and $\mathrm{Xe}$, whereas the $a^{4} \mathrm{D}_{7 / 2}$ presented in a previous publication (Ref. 10) results from excitation of Mn atoms isolated in tetravacancy (red) matrix sites. $\nu$ indicates the emission band center in wavenumber units. The results of $W_{p}$ fits of the emission band profiles allowed the assignment of ZPL. Crystal field splitting patterns is denoted by CFS and the matrix shift by $\delta$-both in wavenumber $\left(\mathrm{cm}^{-1}\right)$ units.

\begin{tabular}{|c|c|c|c|c|c|}
\hline System & Electronic config. & $\nu\left(\mathrm{cm}^{-1}\right)$ & Assignment & $\mathrm{CFS}\left(\mathrm{cm}^{-1}\right)$ & $\delta\left(\mathrm{cm}^{-1}\right)$ \\
\hline \multicolumn{6}{|c|}{$\operatorname{Mn}\left(b^{4} \mathrm{D}_{7 / 2}\right) /$ RG-blue site } \\
\hline \multirow[t]{3}{*}{$\mathrm{Mn} / \mathrm{Ar}$} & $3 d^{5} 4 s^{2}$ & 30205 & ZPL 1 & & -148 \\
\hline & & 30168 & ZPL 2 & 37 & \\
\hline & & 30141 & ZPL 3 & 27 & \\
\hline \multirow[t]{3}{*}{$\mathrm{Mn} / \mathrm{Kr}$} & $3 d^{5} 4 s^{2}$ & 30204 & ZPL 1 & & -150 \\
\hline & & 30171 & ZPL 2 & 33 & \\
\hline & & 30149 & ZPL 3 & 22 & \\
\hline \multirow[t]{3}{*}{$\mathrm{Mn} / \mathrm{Xe}$} & $3 d^{5} 4 s^{2}$ & 30204 & ZPL 1 & & -151 \\
\hline & & 30177 & ZPL 2 & 27 & \\
\hline & & 30157 & ZPL 3 & 20 & \\
\hline \multicolumn{6}{|c|}{$\operatorname{Mn}\left(a{ }^{4} \mathrm{D}_{7 / 2}\right) / \mathrm{RG}-$ red site } \\
\hline \multirow[t]{3}{*}{$\mathrm{Mn} / \mathrm{Ar}$} & $3 d^{6} 4 s^{1}$ & 23388 & ZPL 1 & & +91 \\
\hline & & 23358 & ZPL 2 & 30 & \\
\hline & & 23352 & ZPL 3 & 6 & \\
\hline \multirow[t]{3}{*}{$\mathrm{Mn} / \mathrm{Kr}$} & $3 d^{6} 4 s^{1}$ & 23374 & ZPL 1 & & +77 \\
\hline & & 23342 & ZPL 2 & 32 & \\
\hline & & 23328 & ZPL 3 & 14 & \\
\hline
\end{tabular}




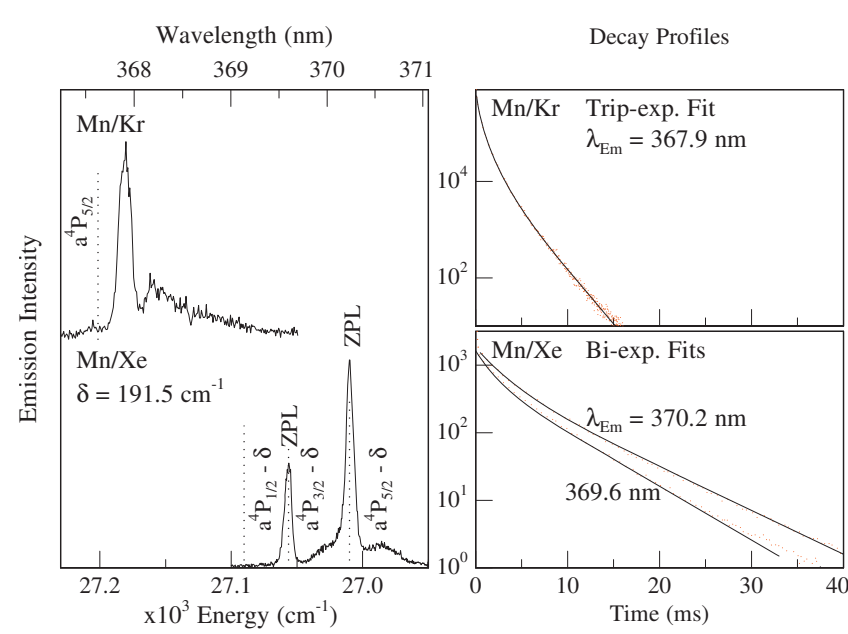

FIG. 7. Spectral and temporal characteristics of the sharp emission present in $\mathrm{Kr}$ and $\mathrm{Xe}$ near $370 \mathrm{~nm}$ in the vicinity of the gas phase $a{ }^{4} \mathrm{P}_{\mathrm{J}} \leftrightarrow a{ }^{6} \mathrm{~S}$ transitions of $\mathrm{Mn}$. The vertical dotted line on the upper left indicates the gas phase position of the $a{ }^{4} \mathrm{P}_{5 / 2} \leftrightarrow a{ }^{6} \mathrm{~S}_{5 / 2}$ transition indicating a very small shift for the red site emission in $\mathrm{Kr}$. The dotted lines presented in the lower right show the three spin-orbit levels of the $a^{4} \mathrm{P}_{\mathrm{J}}$ state redshifted by $\delta$ $=191.5 \mathrm{~cm}^{-1}$, allowing easy identification of the pair of lines on the $\mathrm{Mn} / \mathrm{Xe}$ system as the $a{ }^{4} \mathrm{P}_{3 / 2}$ and $a{ }^{4} \mathrm{P}_{5 / 2} \leftrightarrow a^{6} \mathrm{~S}_{5 / 2}$ transitions, respectively. On the right decays of the three dominant emission bands are shown. The results of trial multiexponential fits of the decay profiles are presented as solid lines.

fitted with double exponential functions as shown on the bottom right of Fig. 7. The major component shows decay times of 12.5 and $15.4 \mathrm{~ms}$ as listed in Table I.

\section{Red site emission}

An emission feature is observed at $368.2 \mathrm{~nm}$ in $\mathrm{Mn} / \mathrm{Kr}$ following red site excitation at $284 \mathrm{~nm}$ (see Fig. 2). The $a{ }^{4} \mathrm{P}_{(\mathrm{J}=5 / 2)} \rightarrow a{ }^{6} \mathrm{~S}$ transition of atomic manganese occurs at $367.62 \mathrm{~nm}$ in the gas phase, thus the $368.2 \mathrm{~nm}$ emission feature present in $\mathrm{Kr}$ is assigned as emission from the $a{ }^{4} \mathrm{P}_{(\mathrm{J}=5 / 2)}$ excited state showing a matrix shift of $63 \mathrm{~cm}^{-1}$ from the gas phase. Fitting the decay profile of this feature required a triple exponential function the result of which is presented in Fig. 7 and the decay times are provided in Table I. No emission feature is observed in this region following blue site excitation in $\mathrm{Kr}$.

In Mn/Ar a weak emission band is observed at $368.4 \mathrm{~nm}$ following red site excitation (see Fig. 2) and due to its proximity to the gas phase $a{ }^{4} \mathrm{P}_{(\mathrm{J}=5 / 2)} \rightarrow a{ }^{6} \mathrm{~S}_{5 / 2}$ transition must originate from the excited $a^{4} \mathrm{P}$ state of atomic $\mathrm{Mn}$. Due to the low intensity of this feature, it was not possible to record a high-resolution spectrum to establish whether this feature is structured or not. No emission features were observed in this region following blue site excitation in Ar.

\section{DISCUSSION}

\section{A. Site occupancy}

In a previous analysis ${ }^{16}$ of the $y^{6} \mathrm{P}, z{ }^{6} \mathrm{P}$, and $z^{8} \mathrm{P}$ absorption/excitation spectra of matrix-isolated atomic manganese, a connection was made between the blue sites in $\mathrm{Ar}$ and $\mathrm{Kr}$ and the single thermally stable site in $\mathrm{Xe}$. This behavior was identified in the linear correlation of the gas phase-matrix shifts and the polarizabilities of the three rare
TABLE III. Predictions of the bond lengths and binding energies of the ground state $\mathrm{Mn} \cdot \mathrm{RG}(\mathrm{RG}=\mathrm{Ar}, \mathrm{Kr}$, and $\mathrm{Xe})$ diatomics obtained with the LP method. For comparison the results of this method are also presented for the $\mathrm{Mg} \cdot \mathrm{RG}$ (Ref. 22) and Na·RG (Ref. 23) diatomics where high quality experimental data exist.

\begin{tabular}{lccccc}
\hline \hline $\mathrm{LP}$ & $\mathrm{R}_{e}(\AA)$ & $\mathrm{D}_{e}\left(\mathrm{~cm}^{-1}\right)$ & $\operatorname{Exp}$ & $\mathrm{R}_{e}(\AA)$ & $\mathrm{D}_{e}\left(\mathrm{~cm}^{-1}\right)$ \\
\hline $\mathrm{Ar}$ & 4.48 & 84.8 & & $\ldots$ & \\
$\mathrm{Kr}$ & 4.54 & 114.6 & & $\ldots$ & $\ldots$ \\
$\mathrm{Xe}$ & 4.63 & 156.6 & & $\ldots$ & $\ldots$ \\
& & & $\mathrm{Mg}$ & & \\
$\mathrm{Ar}$ & 4.55 & 89.4 & & 4.49 & 65 \\
$\mathrm{Kr}$ & 4.59 & 121.6 & & $\cdots$ & $\cdots$ \\
$\mathrm{Xe}$ & 4.68 & 167.7 & & 4.56 & 94 \\
& & & $\mathrm{Na}$ & & \\
$\mathrm{Ar}$ & 5.07 & 79.8 & & 5.01 & 41.6 \\
$\mathrm{Kr}$ & 5.08 & 115 & & 4.92 & 68.4 \\
$\mathrm{Xe}$ & 5.12 & 171 & & 4.95 & 117 \\
\hline \hline
\end{tabular}

gases. A similar correlation was found between the red sites in Ar and Kr. Currently, neither spectroscopic nor high level $a b$ initio potentials exist for the ground states of the $\mathrm{Mn} \cdot \mathrm{RG}$ $(\mathrm{RG}=\mathrm{Ar}, \mathrm{Kr}$, and $\mathrm{Xe})$ diatomics, so the sites occupied by atomic manganese in rare gas matrices cannot be definitively identified. Despite this shortcoming, reliable bond lengths can be predicted for the $\mathrm{Mn} \cdot \mathrm{RG}$ diatomics from a knowledge of the dispersive forces in these molecules. A refinement of this approach has been presented by Luiti and Pirani ${ }^{21}$ (LP). Using the ionization potentials and polarizabilities $(\alpha)$ of atomic $\mathrm{Mn}$ and the rare gas atoms, ground state bond lengths of $4.48,4.54$, and $4.63 \AA$ are obtained for the $\mathrm{Mn} \cdot \mathrm{RG}$ diatomics. These values and LP predictions for bond lengths of the known Mg· RG (Ref. 22) and Na·RG (Ref. 23) diatomics are presented in Table III. It is evident in the comparisons shown there with experimental data that the LP method overestimates the bond lengths by only about $5 \%$. The bond length predictions indicate strong similarities between the $\mathrm{Mn} \cdot \mathrm{RG}$ and $\mathrm{Mg} \cdot \mathrm{RG}$ systems and dissimilarities with the $\mathrm{Na} \cdot \mathrm{RG}$ system. Thus occupancy of metal atoms in smaller sites will be favored in the $\mathrm{Mn} / \mathrm{RG}$ systems compared to what has been found in MD calculations ${ }^{12}$ of the site occupancy in the $\mathrm{Na} / \mathrm{RG}$ systems.

Consistent with these findings, the $288.2 \mathrm{~nm}$ band in Xe was attributed previously ${ }^{16}$ by us to $\mathrm{Mn}$ atom occupying single substitutional sites (SV) and from the linear polarizability dependence of the blue site absorptions in Ar and $\mathrm{Kr}$, these sites are similarly assigned. Based on $\mathrm{Na} / \mathrm{RG}$ molecular dynamics calculations, ${ }^{12}$ the red absorption bands in Ar and $\mathrm{Kr}$ are attributed to larger TV sites. In summary, the blue site $y{ }^{6} \mathrm{P}$ state absorption/excitation bands in $\mathrm{Ar}, \mathrm{Kr}$, and $\mathrm{Xe}$ are attributed to SV site occupancy, while the red sites in Ar and $\mathrm{Kr}$ are ascribed to TV sites.

\section{B. State assignments}

Table I presents the photophysical characteristics and excited state assignments of the emission features produced with excitation of the $3 d^{5} 4 s 4 p \quad y{ }^{6} \mathrm{P} \leftarrow 3 d^{5} 4 s^{2}$ a ${ }^{6} \mathrm{~S}$ transition of atomic manganese. From the entries in this table it is 


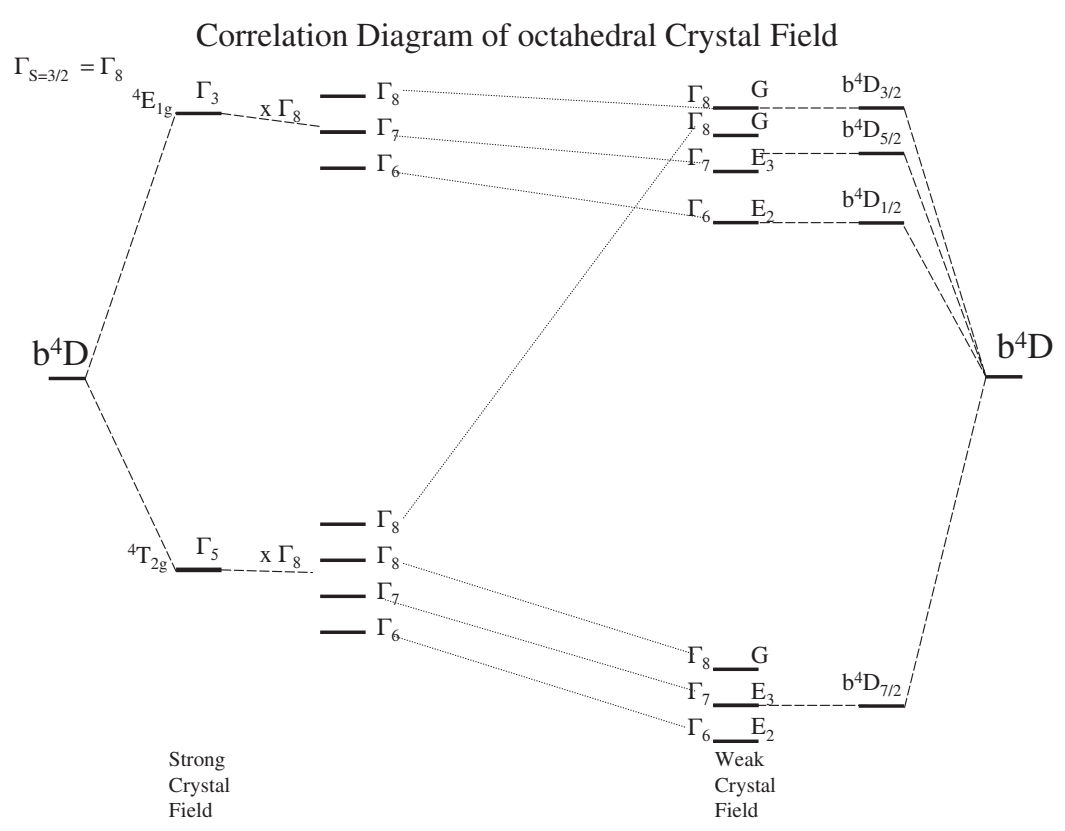

FIG. 8. A correlation diagram of the crystal fieldinduced fine structure of the $\mathrm{J}=7 / 2$ spin-orbit level of the $a^{4} \mathrm{D}_{7 / 2}$ state in a cubooctahedral site. The weak field energy splittings depicted on the right are the gas phase for the spin-orbit levels shown to scale. The strong field splitting shown on the middle left is not to scale as the Mn-RG interaction energies are not known. The key result of this correlation diagram is the existence of three $\mathrm{CF}$ split levels $\left(G, \mathrm{E}_{1}\right.$, and $\left.\mathrm{E}_{2}\right)$ with degeneracies of 4:2:2 for the $J=7 / 2$ spin-orbit level.

evident that the observed emissions fall into one of two distinct categories. Thus the broad emission bands at 288, 289, and $354 \mathrm{~nm}$ in $\mathrm{Ar}, \mathrm{Kr}$, and $\mathrm{Xe}$ respectively, all of which involve nanosecond lifetimes, are clearly resonance $y^{6} \mathrm{P}$ $\rightarrow a{ }^{6} \mathrm{~S}$ transitions. Despite having similar lifetimes, the ${ }^{6} \mathrm{P}$ state emission bands in $\mathrm{Ar}$ and $\mathrm{Kr}$ are quite different to $\mathrm{Xe}$ as the former exhibit moderate Stokes $\left(\sim 1000 \mathrm{~cm}^{-1}\right)$ shifts and linewidths $\left(<500 \mathrm{~cm}^{-1}\right)$ but for Mn $y{ }^{6} \mathrm{P}$ state in $\mathrm{Xe}$, much larger values $\left(\delta=7500, \Delta=\sim 1400 \mathrm{~cm}^{-1}\right)$ are observed. This contrasting behavior has already been observed in $p \rightarrow s$ transitions of several metal atom systems. The best documented ${ }^{9}$ cases are the $\mathrm{Hg}, \mathrm{Cd}$, and $\mathrm{Zn}$ systems.

The second emission category has millisecond lifetimes and exhibits small matrix shifts from the gas phase transitions. Because of the small shifts and long lifetimes, quartet spin state assignments can be made even though gas phase lifetimes are not available. As indicated in Table I, the narrow bands in the 330 and $370 \mathrm{~nm}$ regions are assigned to the $b^{4} \mathrm{D}$ and $a^{4} \mathrm{P}$ states, respectively. Both of these states arise from the $3 d^{5} 4 s^{2}$ configuration identical to that of the ground ${ }^{a}{ }^{6} \mathrm{~S}_{5 / 2}$ state and entirely consistent with the observation of narrow emission lines. However, the extent of phonon structure on the $b^{4} \mathrm{D}$ varies considerably between the sites occupied. In an attempt to identify the origin of this variation, the different lineshapes presented by these and other D states will now be assessed.

\section{D state emission}

Inspection of the spectra presented in Fig. 4 reveals that blue (SV) site excitation produces three very similar emission features in $\mathrm{Ar}, \mathrm{Kr}$, and $\mathrm{Xe}$ matrices. The most intense feature has a matrix shift of $150 \mathrm{~cm}^{-1}$ from the gas phase $3 d^{5} 4 s^{2} \quad b^{4} \mathrm{D}_{(\mathrm{J}=7 / 2)} \rightarrow 3 d^{5} 4 s^{2} \quad a^{6} \mathrm{~S}_{5 / 2}$ transition that is quite independent of the host. The $W_{p}$ function fit of this emission, shown in Fig. 6 for $\mathrm{Mn} / \mathrm{Kr}$, was used successfully in the two other hosts. Overall, very weak electron-phonon coupling
( $\mathrm{S}=0.23)$ was used but most significantly, the existence of three resolved ZPLs was identified for the blue site, near-UV emission of all three hosts.

The presence of multiple ZPLs on a single spin-orbit level of the $b^{4} \mathrm{D}$ state requires an investigation of the influence of the crystal field of the lattice site on the $J=7 / 2$ level. A correlation diagram, showing the origins of the crystal field splitting (CFS) in octahedral symmetry, is shown in Fig. 8 for all four spin-orbit levels of the ${ }^{4} \mathrm{D}$ state. The portion of the diagram appropriate for the $b^{4} \mathrm{D}_{7 / 2}$ state of matrixisolated atomic manganese is on the bottom right hand side where the CFS is less than the spin-orbit splitting (SOS). Group theory predicts ${ }^{24}$ that fields of cubic symmetry will produce three energetically distinct levels $\mathrm{G}, \mathrm{E}_{3}$, and $\mathrm{E}_{2}$ with degeneracies $^{25}$ of 4,2 , and 2 , respectively, from an original value of $8(2 \mathrm{~J}+1)$ for the $\mathrm{J}=7 / 2$ level. If the CFS levels are populated statistically with $y^{6} \mathrm{P}$ state excitation, then emission intensity ratios of 2:1:1 will occur. $W_{p}$ fits of the recorded near-UV emission bands, shown in Fig. 6 for $\mathrm{Mn} / \mathrm{Kr}$, exhibit this intensity ratio for the three resolved ZPLs. Similar patterns were found for the blue site emissions in Xe and Ar with, as shown in Fig. 4, the magnitude of the splitting increasing in this series. In contrast, red site emission of the $\mathrm{J}=7 / 2$ level in the $b^{4} \mathrm{D}$ state exhibits a single, sharp ZPLs in both $\mathrm{Ar}$ and $\mathrm{Kr}$ only slightly shifted from the gas phase transition. If the red site emission bands have CFS, it is less than the $5 \mathrm{~cm}^{-1}$ resolution limit of our emission monochromator.

The intensity distribution of the ZPLs in the near-UV $\left(3 d^{5} 4 s^{2} b^{4} \mathrm{D}_{\mathrm{J}=7 / 2}\right)$ blue site emission is reminiscent of the $428 \mathrm{~nm}$ bands previously observed by our group ${ }^{10}$ for atomic Mn isolated in the red (TV) site of solid Ar and Kr. This emission, shown in Fig. 9 for Mn/Ar, is produced most efficiently with excitation of the $z^{6} \mathrm{P} \leftarrow a{ }^{6} \mathrm{~S}$ transition and has been assigned to the $3 d^{6} 4 s^{1} a{ }^{4} \mathrm{D}_{(\mathrm{J}=7 / 2)}$ state. As the $428 \mathrm{~nm}$ bands also involves emission from the $J=7 / 2$ level, the same group theoretical analysis is valid here but tetrahedral symmetry is used for the TV (red) site occupied. The $W_{p}$ fits of the emission at 12 and $25 \mathrm{~K}$ reveal, as shown in Fig. 9, small 


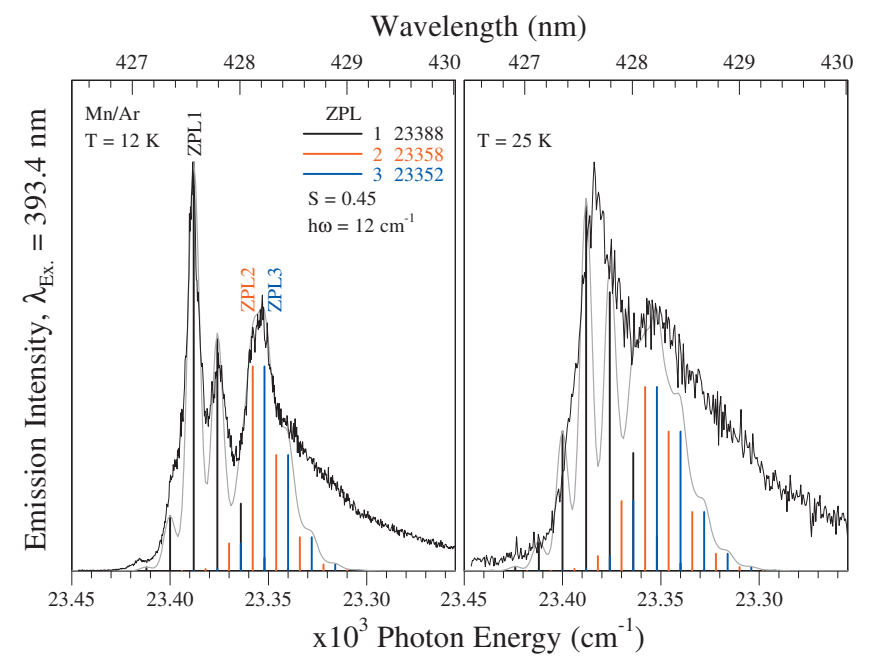

FIG. 9. A comparison of the high-resolution $428 \mathrm{~nm} a{ }^{4} \mathrm{D}_{7 / 2}$ state emission recorded at two temperatures for the dominant red site of $\mathrm{Mn} / \mathrm{Ar}$ with fits obtained with three $W_{p}$ lineshape functions. The locations of the three ZPLs extracted are indicated on the plot in wavenumber units. The long, red wing unaccounted for in the simulation arises from broad, blue site emission centered at $440 \mathrm{~nm}$

$\mathrm{S}$ values of 0.45 . As found for the near-UV blue site emission, the three ZPLs in the $428 \mathrm{~nm}$ emission exhibit the intensity ratios $2: 1: 1$. In contrast, the blue site $440 \mathrm{~nm}$ emission of the $3 d^{6} 4 s^{1} \quad a^{4} \mathrm{D}_{(\mathrm{J}=7 / 2)}$ state is broad and featureless. This emission was previously fit ${ }^{10}$ using a single $W_{p}$ function with an $\mathrm{S}$ value of 6 indicating moderately strong electronphonon coupling.

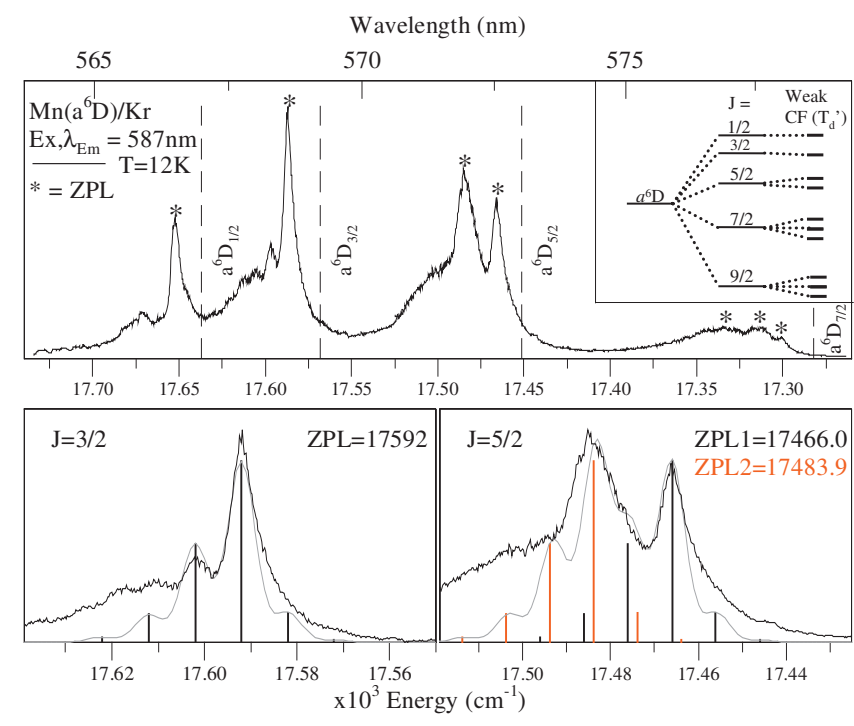

FIG. 10. High-resolution laser excitation spectra recorded at $12 \mathrm{~K}$ for the metastable $a^{6} \mathrm{D}_{9 / 2}$ state emission of atomic manganese in an annealed $\mathrm{Kr}$ sample. The spectrum was recorded with rhodamine 590 monitoring the emission at $585.7 \mathrm{~nm}$ previously assigned to the $a^{6} \mathrm{D}_{9 / 2} \rightarrow a^{6} \mathrm{~S}_{5 / 2}$ transition. The dashed vertical lines indicate the gas phase positions of the excited spin-orbit levels of the $a^{6} \mathrm{D}_{\mathrm{J}} \leftrightarrow a^{6} \mathrm{~S}$ state for $\mathrm{J}=1 / 2,3 / 2,5 / 2$, and $7 / 2$ levels. The presence of multiple zero-phonon lines in excitation is indicated by the asterisks. The inset on the top right illustrates the effect of a weak CF on the spin-orbit levels of the $a^{6} \mathrm{D}_{\mathrm{J}}$ states of atomic manganese isolated in a matrix site of tetrahedral symmetry $\left(T_{d}^{\prime}\right)$. The bottom panels present simulations of the resolved features in the $\mathrm{Mn} / \mathrm{Kr}$ excitation band profiles recorded for the $a^{6} \mathrm{D}_{\mathrm{J}} \leftarrow a^{6} \mathrm{~S} \mathrm{~J}=3 / 2$ and 5/2 (left and right) recorded at $12 \mathrm{~K}$. The locations of the ZPLs are shown by $\nu_{0,0}$ in wavenumber units. The band profiles were reproduced by centering Gaussian line shapes (FWHM $6.6 \mathrm{~cm}^{-1}$ ) for the $W_{p}$ distributions described in the text.
TABLE IV. Results of lineshape simulations of the $\operatorname{Mn}\left(a{ }^{6} \mathrm{D}_{\mathrm{J}} \leftarrow a{ }^{6} \mathrm{~S}\right) / \mathrm{Kr}$ excitation and $\operatorname{Mn}\left(a{ }^{4} \mathrm{D}_{7 / 2} \rightarrow a{ }^{6} \mathrm{~S}\right) / \mathrm{Kr}$ and Ar emission spectra using the $W_{p}$ optical function as described in the text. The $W_{p}$ fit parameters $\nu_{0,0}$ and $\hbar \omega$ are presented in wavenumber $\mathrm{cm}^{-1}$ units while the Huang-Rhys factor $\mathrm{S}$, is unitless. CFS of matrix-isolated atomic manganese is identified as the difference between adjacent zero-phonon lines for a given spin-orbit state.

\begin{tabular}{|c|c|c|c|c|}
\hline $\mathrm{J}$ & $\mathrm{S}$ & $\mathrm{ZPL}\left(\mathrm{cm}^{-1}\right)$ & CFS & $\hbar \omega\left(\mathrm{cm}^{-1}\right)$ \\
\hline \multicolumn{5}{|c|}{$\operatorname{Mn}\left(a^{6} \mathrm{D}_{\mathrm{J}}\right) / \mathrm{Kr}$} \\
\hline $1 / 2$ & 0.4 & 17662 & $\cdots$ & 10 \\
\hline $3 / 2$ & 0.4 & 17592 & $\cdots$ & 10 \\
\hline \multirow[t]{2}{*}{$5 / 2$} & 0.4 & 17484 & 18 & 10 \\
\hline & & 17466 & & \\
\hline \multirow[t]{3}{*}{$7 / 2$} & 0.4 & 17295 & 12 & 10 \\
\hline & & 17307 & 21 & \\
\hline & & 17328 & & \\
\hline \multirow[t]{4}{*}{$9 / 2$} & 0.4 & 17072.5 & 14.6 & 10 \\
\hline & & 17087.1 & 18.5 & \\
\hline & & 17105.6 & & \\
\hline & & $\operatorname{Mn}\left(a^{4} \mathrm{D}_{7 / 2}\right.$ & & \\
\hline \multirow[t]{3}{*}{$\mathrm{Kr}$} & 0.4 & 23328 & 14 & 10 \\
\hline & & 23342 & 32 & \\
\hline & & 23374 & & \\
\hline \multirow[t]{3}{*}{$\mathrm{Ar}$} & 0.45 & 23352 & 6 & 12 \\
\hline & & 23358 & 30 & \\
\hline & & 23388 & & \\
\hline
\end{tabular}

In an earlier publication ${ }^{20}$ we presented laser excitation spectroscopy of the metastable $3 d^{6} 4 s^{1} a^{6} \mathrm{D}$ state of Mn atoms recorded by monitoring emission at $585.8 \mathrm{~nm}$. This emission wavelength corresponds to red site occupancy. With direct excitation of the $a^{6} \mathrm{D}_{\mathrm{J}} \leftarrow a{ }^{6} \mathrm{~S}$ transition the five spinorbit levels of the $a^{6} \mathrm{D}$ state were clearly identified because the gas phase splitting between spin-orbit levels was maintained in the matrix environment. In a recent $W_{p}$ lineshape analysis conducted $^{26}$ on the distinct spin-orbit levels, multiple ZPLs were identified for $\mathrm{J}=5 / 2,7 / 2$, and $9 / 2$ while single ZPLs were sufficient for the $\mathrm{J}=3 / 2$ and $1 / 2$ levels. A summary of the fits conducted is presented in Fig. 10 and the parameters extracted are collected in Table IV. This behavior is entirely consistent with group theoretical predictions of CFS for the five resolved spin-orbit levels in the range $J$ $=1 / 2$ to $9 / 2$. Small $S$ values $(=0.4)$ were extracted in these fits, indicative of weak electron-phonon coupling for the $3 d^{6} 4 s^{1} \quad a^{6} \mathrm{D}$ state of atomic $\mathrm{Mn}$ in the red, TV site. The blue site emission of the $3 d^{6} 4 s^{1} a^{6} \mathrm{D}$ state is broad and located at $628 \mathrm{~nm}$. A $W_{p}$ fit of this emission band revealed an $\mathrm{S}$ value of 6 indicating moderately strong electron-phonon coupling in the smaller site.

\section{CONCLUSIONS}

Considering the above observations, a pattern emerges that the $3 d^{6} 4 s^{1}$ orbital occupancy produces narrow emission bands $\left(a^{6} \mathrm{D}_{9 / 2} / 585.8 \mathrm{~nm}, a^{4} \mathrm{D}_{7 / 2} / 428 \mathrm{~nm}\right)$ with resolved CFS when the Mn atom is isolated in the larger (red) TV site. Conversely, broad, shifted emission $\left(a^{6} \mathrm{D} / 628 \mathrm{~nm}\right.$, $a^{4} \mathrm{D} / 440 \mathrm{~nm}$ ) arises when $\mathrm{Mn}$ is in the smaller (blue) substitutional site. In contrast, the $3 \mathrm{~d}^{5} 4 \mathrm{~s}^{2}$ orbital occupancy produces resolved CFS emission when $\mathrm{Mn}$ is in the blue site 
TABLE V. A summary of the combined influences of site size and electronic configuration on the luminescence bandshapes of matrix-isolated atomic manganese. Although not present in the Mn/RG systems, extrapolations of these influences into larger cubic vacancies, such as the hexavacancy (HV) site, are also provided. The $\mathrm{S}$ values listed are the Huang-Rhys factors extracted in the $W_{p}$ optical function fits conducted in the present study of the $3 d^{5} 4 s^{2}$ configuration and in previous (Refs. 10 and 26) work on the $3 d^{6} 4 s^{1}$ configuration. The abbreviations SOS and CFS indicate resolved spin-orbit splitting and crystal field splitting, respectively.

\begin{tabular}{|c|c|c|c|c|}
\hline \multirow[b]{2}{*}{ Electronic config. } & \multirow[b]{2}{*}{ Term } & \multicolumn{3}{|c|}{ Site of isolation } \\
\hline & & SV & TV & HV predicted \\
\hline \multirow[t]{6}{*}{$3 d^{5} 4 s^{2}$} & $a{ }^{4} \mathrm{P}$ & SOS & SOS & SOS \\
\hline & & Narrow & Narrow & Narrow \\
\hline & & $\mathrm{S}=0.0$ & $\mathrm{~S}=0.0$ & \\
\hline & $b^{4} \mathrm{D}$ & CFS & SOS & SOS \\
\hline & & Narrow & Narrow & Narrow \\
\hline & & $\mathrm{S}=0.4$ & $\mathrm{~S}=0.0$ & \\
\hline \multirow[t]{6}{*}{$3 d^{6} 4 s^{1}$} & $a^{4} \mathrm{D}$ & & CFS & SOS \\
\hline & & Broad & Narrow & Narrow \\
\hline & & $S=6.0$ & $S=0.45$ & \\
\hline & $a^{6} \mathrm{D}$ & & CFS & SOS \\
\hline & & Broad & Narrow & Narrow \\
\hline & & $S=6.0$ & $\mathrm{~S}=0.4$ & \\
\hline
\end{tabular}

$\left(b{ }^{4} \mathrm{D} / 331-332 \mathrm{~nm}\right)$ and unshifted emission $\left(b{ }^{4} \mathrm{D} /\right.$ $329 \mathrm{~nm}$ ), free of any discernable phonon structure or splitting, when in the larger red site. These observations point to the roles played by (1) the orbital occupancy of the states involved in a transition and (2) the site occupancy of the metal atom in the lattice. The range of behavior exhibited by matrix-isolated atomic manganese is summarized in Table V. It extends from the narrowest lines exhibited when the orbital occupancy is unchanged in the electronic transition (e.g., $3 d^{5} 4 s^{2} \quad b^{4} \mathrm{D}_{7 / 2} \rightarrow 3 d^{5} 4 s^{2} \quad a^{6} \mathrm{~S}_{5 / 2}$ ) and the larger (TV) sites are occupied, to the broadest bands which accompany a change in the orbital occupancy (e.g., $3 d^{6} 4 s^{1} b^{4} \mathrm{D}$ or $\left.a^{6} \mathrm{D} \rightarrow 3 d^{5} 4 s^{2} a^{6} \mathrm{~S}\right)$ when the metal atom occupies the smaller SV sites. Intermediate behavior, exhibiting resolved CFS, is found for transitions not involving changes in orbital occupancy but for atoms isolated in small SV sites.

If the site occupancy assignments are correct (that the blue sites correspond to $\mathrm{Mn}$ atoms in SVs and the red sites involve TVs) then the critical Mn-RG distances can be identified where CFS is manifested since the sizes of these regular sites of the pure rare gases are known. Thus for the $3 d^{5} 4 s^{2}$ orbital occupancy it is between 3.988 (SV) and 4.676 (TV) $\AA$ in $\mathrm{MnKr}$ and for the $3 d^{6} 4 s^{1}$ orbital occupancy, CFS has already occurred at $4.676 \AA$. An interesting trend detected in the blue site $3 d^{5} 4 s^{2} b{ }^{4} \mathrm{D}_{7 / 2}$ level is that the CFS increases in the series $\mathrm{Ar}-\mathrm{Xe}$. This suggests that the site size plays a more important role in determining the extent of the splitting than the strength of interaction. It would be expected that the increased polarizability of xenon would give rise to the strongest interaction of the three rare gases studied but this is evidently not reflected in the splittings present in the recorded spectra.

A group theoretical analysis ${ }^{26}$ of crystal field perturbations of discrete spin-orbit levels indicates that for all $\mathrm{J}$ values greater than $3 / 2$, splitting should in theory be exhibited. This raises the interesting possibility of observing CFS of $\mathrm{P}$ terms or even the $\mathrm{J}=5 / 2$ level of the spherically symmetric ${ }^{6} \mathrm{~S}$ (A) ground state of matrix isolated atomic manganese. A very significant observation made in this regard concerns the $3 d^{5} 4 s^{2} a^{4} \mathrm{P}$ state at approximately $370 \mathrm{~nm}$ which in $\mathrm{Mn} / \mathrm{Xe}$ exhibits a pair of narrow, nonsplit emission features for the $J=5 / 2$ and $3 / 2$ spin-orbit levels. As demonstrated elsewhere, group theory predicts that the $5 / 2$ level will split into two levels, but no such splitting is evident in the spectra recorded. With the resolving power of our emission system, the $\mathrm{J}=5 / 2$ spin-orbit level shows no splitting even though this system has only blue site occupancy in which CFS has been found most pronounced. Thus for terms derived from a common configuration, in this case $3 d^{5} 4 s^{2}$, this behavior would indicate that the spin-orbit levels derived from $\mathrm{P}$ terms are less prone to CFS than those derived from D terms. It is well known that crystal fields of cubic symmetry do not induce splitting of $\mathrm{P}$ terms so on the basis of the present observations, it would appear that the spatial nature of the term is more important than the degeneracy of the spin-orbit level. More systems need to be studied before a generalization can be provided.

As mentioned earlier, even the symmetric ${ }^{6} \mathrm{~S}$ (A) ground state of atomic manganese should in theory be prone to CFS since it has a $J$ value of $5 / 2$. In an ESR study of ground state $\mathrm{Mn}$ atoms isolated in $\mathrm{Ne}$ and $\mathrm{Ar}$ matrices, Weltner and co-workers $^{27}$ identified features in the recorded spectra which indicated zero-field splitting of the $\mathrm{S}$ term. The magnitude of the ZFS was $|\mathrm{D}|=0.0071 \mathrm{~cm}^{-1}$ in neon ${ }^{28}$ and smaller still in Ar. These values are four orders of magnitude less than the $30 \mathrm{~cm}^{-1}$ CFS present on the optical transitions examined in the present study and clearly will not affect the splitting of excitation or emission bands. Nevertheless these magnetic resonance observations do reveal the power of group theoretical methods to analyze the manifestation of competing crystal field and spin-orbit effects in optical spectroscopies.

\section{ACKNOWLEDGMENTS}

This research was funded by the Irish Government Enterprise Ireland, SC/98/403 Basic Science research. The iCCD camera used in this work was acquired with the financial support of Science Foundation Ireland (SFI), Investigator Grant No. 02/IN.1/B032. O.B. gratefully acknowledges the award of a Ph.D. studentship from Embark Initiative Irish Research Council for Science and Engineering (IRCSET) and a John \& Pat Hume scholarship from N.U.I.-Maynooth. M.C. gratefully acknowledges receipt of an EU Marie Curie Re-Integration grant.

${ }^{1}$ C. Crepin-Gilbert and A. Tramer, Int. Rev. Phys. Chem. 18, 485 (1999). ${ }^{2}$ V. E. Bondybey, J. Chem. Phys. 68, 1308 (1978).

${ }^{3}$ M. J. Pellin, D. M. Gruen, T. Fischer, and T. Foosneas, J. Chem. Phys. 79, 5871 (1983).

${ }^{4}$ T. A. Cellucci and E. R. Nixon, J. Phys. Chem. 89, 1991 (1985) and references cited therein to earlier work; In particular, M. T. McKenzie, Ph.D. thesis, University of Pennsylvania, 1983.

${ }^{5}$ H. O. Wiggenhauser, W. Schroeder, and D. M. Kolb, J. Chem. Phys. 88, 3434 (1988) 
${ }^{6}$ S. A. Mitchell, J. Farrell, G. A. Kenney-Wallace, and G. A. Ozin, J. Am. Chem. Soc. 102, 7702 (1980).

${ }^{7}$ V. A. Bracken, P. Gürtler, and J. G. McCaffrey, J. Chem. Phys. 107, 5290 (1997).

${ }^{8}$ B. Healy and J. G. McCaffrey, J. Chem. Phys. 110, 3903 (1999)

${ }^{9}$ M. A. Collier and J. G. McCaffrey, J. Chem. Phys. 119, 11878 (2003).

${ }^{10}$ M. A. Collier and J. G. McCaffrey, J. Chem. Phys. 122, 184507 (2005).

${ }^{11}$ M. A. Collier, Ph. D. thesis, National University of Ireland-Maynooth, 2004.

${ }^{12}$ M. A. Ryan, M. Collier, P. de Pujo, C. Crépin, and J. G. McCaffrey, J. Phys. Chem. A 114, 3011 (2010).

${ }^{13}$ NIST Atomic Spectra Database, website: http://physics.nist.gov/ PhysRefData/ASD/ (last accessed December 2009).

${ }^{14}$ J. Shakhsemampour, "Absorption and magnetic circular dichroism of transition metal atoms and small clusters isolated in noble gas matrices," Ph.D. thesis, University of Florida, 1983.

${ }^{15}$ J. C. Rivoal, J. Shakhsemampour, K. K. Zeringue, and M. Vala, Chem. Phys. Lett. 92, 313 (1982)

${ }^{16}$ M. A. Collier and J. G. McCaffrey, J. Chem. Phys. 122, 054503 (2005).

${ }^{17}$ C. W. Struck and W. H. Fonger, Understanding Luminescence Spectra and Efficiency Using $W_{p}$ and Related Functions (Springer, Berlin, 1991).

${ }^{18}$ The emission bands in the visible spectral region $(\lambda>400 \mathrm{~nm})$ have been analyzed in earlier work, see Ref. 10 for details.
${ }^{19}$ S. M. Younger, J. R. Fuhr, G. A. Martin, and W. L. Wiese, J. Phys. Chem. Ref. Data 7, 495 (1978)

${ }^{20}$ M. A. Collier, M. A. Ryan, and J. G. McCaffrey, J. Chem. Phys. 123, 044508 (2005).

${ }^{21}$ P. Cambi, D. Cappelletti, G. Luiti, and F. Pirani, J. Chem. Phys. 95, 1852 (1991).

${ }^{22}$ J. G. McCaffrey, A. Leung, D. J. Bellert, and W. H. Breckenridge, Chem. Phys. Lett. 302, 113 (1999).

${ }^{23}$ D. Schwarzhans and D. Zimmermann, Eur. Phys. J. D 22, 193 (2003) (and references cited therein).

${ }^{24}$ B. diBartolo, Optical Interactions in Solids (Wiley, New York, 1968), p. 204.

${ }^{25}$ B. S. Tsukerblat, Group Theory in Chemistry and Spectroscopy (Dover, New York, 2006), p. 258

${ }^{26}$ O. Byrne, M.A. Collier, M.A. Ryan and J.G. McCaffrey, "Crystal field splitting on $\mathrm{D} \leftrightarrow \mathrm{S}$ transitions of atomic manganese isolated in solid Krypton," J. Low Temp. Physics (in press).

${ }^{27}$ R. J. van Zee, D. A. Garland, and W. Weltner, J. Chem. Phys. 85, 3237 (1986).

${ }^{28}$ W. Weltner, Magnetic Atoms and Molecules (van Nostrand Reinhold, New York, 1983), pp. 28 and 29. 